\title{
Controlled release alginate-chitosan microspheres of tolmetin sodium prepared by internal gelation technique and characterized by response surface modeling
}

\author{
Mahmoud M. A. Elsayed ${ }^{\circledR 1, *}$

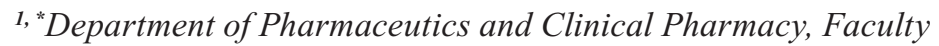 \\ of Pharmacy, Sohag University, Sohag, Egypt
}

\begin{abstract}
Tolmetin sodium (TS) is a powerful non-steroidal mitigating drug for the treatment of rheumatoid joint inflammation, osteoarthritis, and adolescent rheumatoid joint pain. In addition to its gastrointestinal (GIT) problems, TS has a short biological half-life (1 hr). In a trial to overcome these side effects and control the rate of (TS) release, chitosan coated alginate microspheres are recommended. A BoxBehnken experimental design was employed to produce controlled release microspheres of TS in the sodium alginate and chitosan copolymers (Alg-Ch) by emulsification internal gelation methodology. The effect of critical formulation variables namely, drug to polymer ratio (D:P ratio), speed of rotation and span $80 \%$ on drug encapsulation efficiency (\% EE), drug release at the end of 2 hours $\left(\operatorname{Rel}_{2}\right)$ and drug release at the end of 8 hours $\left(\mathrm{Rel}_{8}\right)$ were analyzed using response surface modeling. The parameters were assessed using the $\mathrm{F}$ test and mathematical models containing only the significant terms were generated for each parameter using multiple linear regression analysis. The produced microspheres were spherical in shape with extensive pores at D:P ratio 1:1 and small pores at a drug to polymer ratio (D:P ratio) 1:3. Differential scanning calorimetry (DSC) affirmed the steady character of TS in microspheres and revealed their crystalline form. All formulation variables examined exerted a significant influence on the drug release, whereas the speed emerged as a lone factor significantly influencing \% EE. Increasing the D: P ratio decreases the release of the drug after two and 8 hours. The increase in speed results in an increase in drug release after two and eight hours. The drug release from the microspheres followed zero order kinetics. TS Alg-Ch microspheres exhibited a significant anti-inflammatory effect on incited rat paw edema after eight hours. These results revealed that the internal gelation technique is a promising method to control TS release and eradicate GIT side effects using Alg-Ch copolymers.
\end{abstract}

Keywords: Tolmetin Sodium. Controlled Release. Alginate. Chitosan. Response Surface.

\section{INTRODUCTION}

TS is an effective anti-inflammatory and painrelieving drug in clinical practice and it represses both isoforms of cyclo-oxygenase enzyme. The inhibition of cyclo-oxygenase enzyme COX-I result in a number of undesirable effects such as GIT complaints.

*Correspondence: M. A. Mahmoud. Department of Pharmaceutics and Clinical Pharmacy Faculty of Pharmacy. Sohag University, Sohag, Egypt. PO Box 82524. Phone: 00201227660470/ 0020934605601. E-mail: Mahmoudalmenshawy@pharm.sohag.edu.eg
Moreover, TS has a short plasma half-life (about 1-2 hours) that necessitates frequent administration of the drug through the daytime (Jelvehgari et al., 2010). Therefore, TS is highly recommended being prescribed in a controlled release dosage form. Furthermore, it would contribute to hold encapsulated TS during emulsification, decrease its loss during microspheres recovery (Palmieri et al., 2002), and may provide a controlled release effect. Consequently, the aim of this work was to control TS release using oral dosage formulations. 
In this paper, a novel method of emulsification/ internal gelation has been recommended as another option to ionic gelation in the microencapsulation of many drugs (Ahmed et al., 2013) including sensitive biologicals, for example, protein drugs (Chan, Lee, Heng, 2002). Alginate microspheres with small particle size and high $\%$ EE can be produced by this methodology (Chan, Lee, Heng, 2002). The trouble in utilizing dispersion/external gelation systems with ionic polysaccharide is that the calcium source $\left(\mathrm{CaCl}_{2}\right)$ is insoluble in the oil phase. As an option, internal gelation of the scattered alginate might be started by discharging $\mathrm{Ca}^{2+}$ from an insoluble complex (calcium salt) through $\mathrm{pH}$ diminishment (Rajinikanth, Sankar, Mishra, 2003, Zou et al., 2011, Ahmed et al., 2013). Alginates, which are normally founded in brown seaweed and algae have gotten much consideration in pharmaceutical dosage forms, especially as a controlled drug delivery vehicle (Chen, Subirade, 2007). In this context, the use of alginate microspheres as an oral delivery system for TS seems very attractive. The alginate network could shield the medication from antagonistic conditions.

Alginate has mucoadhesive properties, which could expand the contact time amongst microspheres and absorptive sites, and in this way could enhance the uptake of the encapsulated drug. The low harmfulness and low immunogenicity of alginate make this polymer a safe network (Silva et al., 2006, Paredes Juárez et al., 2014). Much attention has been given in recent years to the use of Alg-Ch polyelectrolyte complex in controlled drug delivery.

Chitosan and its subordinates generate particular interest as a biodegradable polymer used in controlling drug release. It is a natural biopolymer consisting of $\beta-1 \rightarrow 4$ linked 2-amino-2-deoxy-glucopyranose $(\mathrm{GlcN})$ and 2-acetamido-2-deoxy- $\beta$-d-glucopyranose (GlcNAc) residues, fabricated industrially on a substantial scale by antacid $N$-deacetylation of chitin, an inexhaustible biopolymer separated from the exoskeleton of shellfish, for example, crabs and shrimps (Thaya et al., 2018). Chitosan-alginate microspheres have been widely used to encapsulate drugs (Thaya et al., 2018). The use of chitosan has been reported for coating alginate microspheres to alter the diffusion rate of encapsulated substances through the interpolymeric chitosan-alginate matrix (Motwani et al., 2008). The prepared microspheres were assessed for their morphology and surface structure, average particle size, production yield, drug loading efficiency, and drug release characteristics.

\section{MATERIAL AND METHODS}

\section{Material}

TS was kindly provided by Minapharm Co. for pharmaceuticals (10th Ramadan, Cairo, Egypt). Sodium alginate (NaA), Low molecular weight (LMW) chitosan: Sigma Chemical Co., St. Louis (USA). Calcium carbonate $\left(\mathrm{CaCO}_{3}\right)$, methylene chloride, glacial acetic acid, light liquid paraffin and potassium dihydrogen orthophosphate, Adwia, El-Nasr Pharm. Chem. Co. (Egypt). Other materials and solvents are of reagent or analytical grade, and they were used without further purification.

\section{Experimental Design}

A Box-Behnken experimental design was utilized to investigate and optimize the formulation parameters of TS microspheres preparation for maximum \% EE and controlled drug delivery after two and 8 hours (Yetilmezsoy, Demirel, Vanderbei, 2009). This design is used as it requires fewer treatment combinations than other designs in cases involving more than two dependent variables (El-Shenawy et al., 2017). The Box- Behnken design is also ratable and contains statistical "missing corners" which may be useful when the experimenter is trying to avoid combined factor extremes. This property prevents a potential loss of data in those cases (Motwani et al., 2008). A 3 factor 3 levels design was employed to design controlled release microspheres of TS. The three independent formulation variables analyzed during the study were $\mathrm{D}: \mathrm{P}$ ratio $\left(\mathrm{X}_{1}\right)$, revolution per minute $\left(\mathrm{X}_{2}\right)$ and span $80 \%\left(\mathrm{X}_{3}\right)$. The selected factors with the actual and coded levels as per the design are represented in Table I. According to this design, 15 formulae of TS microspheres were prepared. Three levels of the speed were used 200, 400 and $600 \mathrm{rpm}$ denoted the values $-1,0$ and +1 in the above design, respectively. Drug: polymer ratio was varied to be (1:1), (1:2) and (1:3), also denoted the values $-1,0$ and +1 , respectively. Lastly, span $80 \%$ was chosen to be $1 \%, 1.5 \%$ and $2 \%$ denoted $-1,0$ and +1 value, respectively. The dependent variables to be tested for the prepared TS microspheres were chosen to be the loading efficiency $\left(\mathrm{Y}_{1}\right)$, release at the end of $2 \mathrm{~h}\left(\mathrm{Y}_{2}\right)$ and release at the end of $8 \mathrm{~h}\left(\mathrm{Y}_{3}\right)$. 
TABLE I - Composition of different formulae of TS-Alg-Ch microspheres

\begin{tabular}{|c|c|c|c|c|c|c|c|}
\hline $\begin{array}{l}\text { Formula } \\
\text { No. }\end{array}$ & $\begin{array}{l}\text { TS } \\
\text { (g) }\end{array}$ & $\begin{array}{l}\text { Ch. } \\
\text { (g) }\end{array}$ & $\begin{array}{l}\text { Na-Alg. } \\
\text { (g) }\end{array}$ & $\begin{array}{c}\mathrm{CaCo}_{3} \\
(\mathrm{~g})\end{array}$ & $\begin{array}{c}\text { Span } 80 \\
(\mathrm{~mL})\end{array}$ & Speed & $\begin{array}{c}\text { Total weight } \\
\text { (g) }\end{array}$ \\
\hline F1 & 0.5 & 0.25 & 0.25 & 0.375 & 1.5 & 200 & 1.375 \\
\hline F2 & 0.5 & 0.25 & 0.25 & 0.375 & 1.0 & 400 & 1.375 \\
\hline F3 & 0.5 & 0.25 & 0.25 & 0.375 & 2 & 400 & 1.375 \\
\hline $\mathrm{F} 4$ & 0.5 & 0.25 & 0.25 & 0.375 & 1.5 & 600 & 1.375 \\
\hline F5 & 0.5 & 0.75 & 0.25 & 0.375 & 1.0 & 200 & 1.875 \\
\hline F6 & 0.5 & 0.75 & 0.25 & 0.375 & 2 & 200 & 1.875 \\
\hline F7 & 0.5 & 0.75 & 0.25 & 0.375 & 1.5 & 400 & 1.875 \\
\hline F8 & 0.5 & 0.75 & 0.25 & 0.375 & 1.5 & 400 & 1.875 \\
\hline F9 & 0.5 & 0.75 & 0.25 & 0.375 & 1.5 & 400 & 1.875 \\
\hline F10 & 0.5 & 0.75 & 0.25 & 0.375 & 1.0 & 600 & 1.875 \\
\hline F11 & 0.5 & 0.75 & 0.25 & 0.375 & 2 & 600 & 1.875 \\
\hline F12 & 0.5 & 1.25 & 0.25 & 0.375 & 1.5 & 200 & 2.375 \\
\hline F13 & 0.5 & 1.25 & 0.25 & 0.375 & 1.0 & 400 & 2.375 \\
\hline F14 & 0.5 & 1.25 & 0.25 & 0.375 & 2 & 400 & 2.375 \\
\hline F15 & 0.5 & 1.25 & 0.25 & 0.375 & 1.5 & 600 & 2.375 \\
\hline
\end{tabular}

\section{Preparation of Alginate Coated Microspheres}

Composition of different suggested formulae of TS microspheres is listed in Table I. Modified encapsulation protocol was used to prepare microspheres (Silva et al., 2006). In brief, the sodium alginate solution was prepared by dissolving $0.25 \mathrm{~g}$ in $30 \mathrm{~mL}$ hot water and then TS was dispersed in this solution using a magnetic stirrer for 10 minutes. A suspension of $\mathrm{CaCO}_{3}$ at $5 \%(\mathrm{w} / \mathrm{v})$ was added to the Alg-TS solution, after homogenization, the mixture was dispersed into paraffin oil (30\% internal phase ratio, $\mathrm{v} / \mathrm{v}$ ) containing different concentrations of span $80 \%$ as an emulsifying agent and was emulsified by stirring at various speeds. After homogenization for $15 \mathrm{~min}, 20 \mathrm{~mL}$ of paraffin oil containing $0.2 \mathrm{~mL}$ glacial acetic acid (acid/Ca molar ratio of 3.5) were added to the w/o emulsion. Mixing was continued for 20 minutes to allow calcium carbonate solubilization and formation of calcium alginate microsphere. After 10 min., a solution of $\mathrm{CaCl}_{2}(0.05 \mathrm{M})$ containing $1 \%$ Tween 80 was added to segment and recoup the gelled microspheres. Microspheres were washed with 0.05 
$\mathrm{M} \mathrm{CaCl}_{2}$ containing $1 \%$ Tween 80 to remove residual oil Microspheres were recovered from oily phase by using an acetate buffer at pH 4.5 (USP XXVII) and progressively washed with this buffer until no more oil was detected by optical microscope observation. Chitosan was used as a polymer in the concentration of $0.5,1$ and $1.5 \%$. A chitosan coat was applied by immersing the microspheres into chitosan solution $(0.5$, 1, $1.5 \%$ w: v) containing $0.05 \mathrm{M} \mathrm{CaCl}_{2}$ (pH 5.5) under magnetic stirring. After $30 \mathrm{~min}$., microspheres were washed as described previously.

\section{Production yield determination}

The yield of the microspheres was determined in triplicate by dividing the weight of the prepared microspheres by the original amount of the Alg-Ch and TS used and the results were expressed as a percentage according to the equation (Jelvehgari et al., 2010).

$\%$ Yield $=$ (Actual weight of microspheres $/$ Total weight of Alg-Ch and TS) $\times 100$

\section{Particle size determination}

The dried microspheres were weighed and sized using USP standard sieve (Rx-86-1, Cole-Palmer Instrument Co., USA). The portion of microspheres remaining on each sieve was gathered and the mean particle size of the microspheres was doled out as the percentage of microspheres retained at each sieve multiplied by the average particle size of the sieve utilized (Sipahigil, Dortunc, 2001). Each investigation was carried out in triplicate.

\section{Determination of drug content}

Digestion method was used to determine TS content in the prepared microspheres (Pandey, Khuller, 2004) and the experiments were carried out in triplicate. One hundred micrograms of TS microspheres were crushed carefully in a glass mortar and a definite weight was transferred to a $100 \mathrm{~mL}$ volumetric flask using phosphate buffer $\mathrm{pH} 7.4$ and completed to the volume using phosphate buffer $\mathrm{pH}$ 7.4. The flask was agitated for $5 \mathrm{~min}$ each hour for $5 \mathrm{~h}$. The sample was filtered TS concentration was determined spectrophotometrically at $324 \mathrm{~nm}$ (Spectrophotometer UV. 1601, Shimadzu Co., Japan). The plain formula was used as a blank and treated with the same procedures.

\section{Microspheres morphology}

The morphology of the microsphere surfaces was investigated using scanning electron microscopy. Microspheres were spread on a carbon double-adhesive layer on a metal holder and gold-coated using an IonSputtering device (Jeol Fine-Coat JFC 1100E, Joel Ltd., Tokyo, Japan). The microspheres were scanned by Scanning Electron Microscope (SEM) (Jeol JSM-5400 LV, Jeol Ltd., Tokyo, Japan).

\section{In-vitro release of TS microspheres}

Dissolution testing of the prepared microspheres equivalent to $100 \mathrm{mg}$ of TS was performed with the rotating basket apparatus according to USP 24 apparatus 1 (SR11 6 Flask, Hanson Co., USA). Hard gelatin capsules No. 2 filled with a known quantity of TS microspheres were used for dissolution study using basket speed of $50 \mathrm{rpm}$ and a temperature of $37{ }^{\circ} \mathrm{C} \pm$ 0.5. Regarding the dissolution medium, fifty $\mathrm{mL}$ of phosphate buffer $\mathrm{pH} 7.4$ was used as the release medium for eight hours (Pasparakis, Bouropoulos, 2006). Three milliliters of each sample were removed at specific intervals throughout the whole $8 \mathrm{hrs}$. The specimens were diluted properly with the dissolution medium and absorbance was measured at the foreordained $\lambda$ max of each medium against a blank of this medium. The withdrawn samples were supplanted with equal volumes of the dissolution medium. All experiments were completed in triplicate.

\section{Regression analysis}

The targeted response parameters were statistically analyzed by applying one-way ANOVA at 0.05 level in Minitab 17 software (Minitab, Inc. USA, Pennsylvania). The dependent variables were evaluated using the $\mathrm{F}$ test and quadratic models of the form $Y=\beta_{0}+\beta_{1} X_{1}$ $+\beta_{2} X_{2}+\beta_{3} X_{1} X_{2}+\beta_{4} X_{1}^{2}+\beta_{5} X_{2}^{2}$ were created for each response variable using multiple linear regression analysis (MLRA), where $\mathrm{Y}$ is the level of the measured response; $\beta_{0}$ is the intercept $\beta_{1}$ to $\beta_{5}$ are the regression coefficients. $X_{1}$ and $X_{2}$ stand for the main effects; $X_{1} X_{2}$ is the interaction between the main effects; $X_{1}^{2}$ and $X_{2}^{2}$ are the quadratic terms of the independent variables that were used to simulate the curvature of the designed sample space. A backward elimination procedure was adopted to fit the data into different predictor equations. 
The quadratic models generated by regression analysis were used to construct the 3-dimensional graphs in which response parameter $\mathrm{Y}$ was represented by a curvature surface as a function of X (Dean, Voss, Draguljić, 2017).

Numerical advancement utilizing attractive quality approach was utilized to find the optimal settings of the independent factors to get the coveted response. A streamlined plan was created by setting imperatives on the independent and dependent variables. The optimized formulation was assessed for the responses and the test esteems acquired were contrasted with those anticipated by the numerical models (Dean, Voss, Draguljić, 2017).

\section{Kinetics of the in-vitro release of TS capsules}

The kinetic parameters for the in vitro release of TS were determined and then analyzed in order to find the proper order of the drug release. Zero and first order kinetics, as well as controlled diffusion or Higuchi diffusion model (Higuchi, 1963).

\section{In-vivo studies}

The anti-inflammatory effect of TS in the chosen formulae, formulae F12, F6, which had the best rank order among the prepared formulae and the commercial TS tablet was studied on rats using the paw edema method. The paw edema induced by injection of carrageenan in the paw was used as an example for the anti-inflammatory bioassay test of TS capsules.

Rats were divided into four groups, each group consisting of six animals. Each group of animals received the specified drug product by oral administration. The animals previously injected with carrageenan, the percentage of inhibition of edema size was measured after 2, 4, 6, 8, 10 and 12 hours.

\section{RESULTS AND DISCUSSION}

\section{Microspheres Morphology}

The microspheres prepared with Alg-Ch copolymers were examined using the light microscope, Figure 1. It can be seen that at $\mathrm{D}: \mathrm{P}$ ratiol:3 the prepared microspheres are spherical in shape with a smoother surface, more intact surface with smaller pores (Figure 1a). Figure 1 (a) reveals that at D:P ratiol:1 there is a hollow cavity for the microspheres by internal gelation, Figure $1(d)$ is the enlarged view of the outer surface, which reveals the clear loose network structure with the larger pores (dark area). In contrast to these results, SEM micrograph of Nimodipine loaded alginate bead treated with chitosan the beads had a spherical shape and showed surface cracks probably caused by the method of preparation which is external gelation in addition to partial collapsing of the polymer network during drying(Rajendran, Basu, 2009).

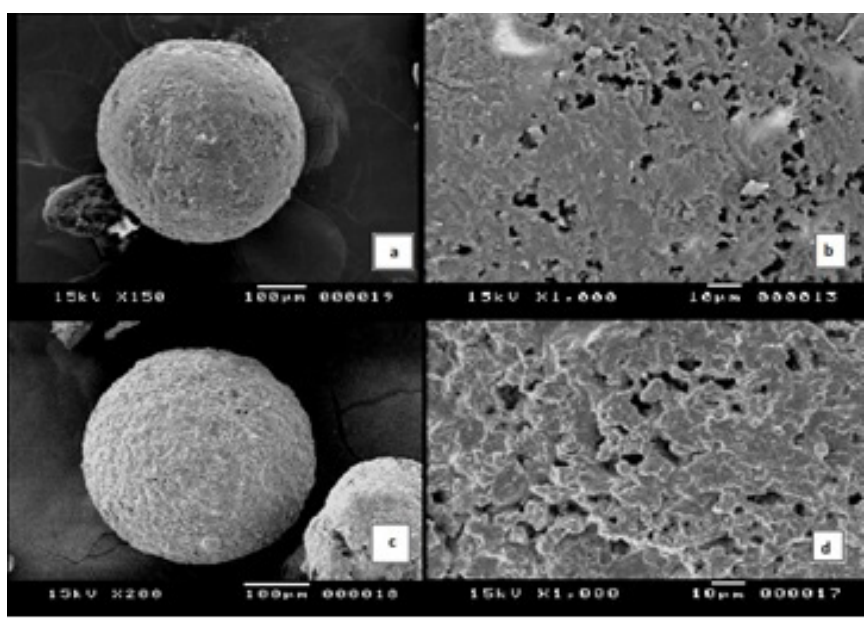

FIGURE 1 - SEM photographs of TS (Ch-Alg) microspheres prepared by internal gelation (a) full view at 1:3 drug to polymer ratio, (b) outer surface at 1:3 drug to polymer ratio, (c) full view at 1:1 drug to polymer ratio, (d) outer surface at 1:1 drug to polymer ratio.

A similar effect on the microspheres shape was stated for salbutamol sulfate microspheres at different ethyl cellulose concentrations (Nath et al., 2010). Those particles were spherical in shape and exhibited porous surfaces. The surface of the drug- loaded microspheres manifested the presence of drug particles as compared to blank microspheres. Surface investigation of the prepared TS microspheres after dissolution studies showed bigger pores suggesting that the drug is released through pores and the kinetics of drug release was diffusion controlled mechanism (Motwani et al., 2008).

Another study for ibuprofen ethyl cellulose revealed that the microspheres had good spherical geometry as evidenced by the SEM photographs. The surface of the microspheres was quite smooth (van Zwol et al., 2008).

Formulae F11, and F15 exhibit the best distribution pattern as the largest weight determined lied between $400 \mathrm{um}-315 \mathrm{um}$, while The remaining formulae F1, F2, F3, F4, F5, F6, F7, F8, F9, F10, F12, F13, and F14 gave the second group of good distribution as the largest weight calculated lied between $890 \mathrm{um}-630 \mathrm{um}$. The 
particle size analysis of Alg-Ch coated microspheres was done using sieve analysis procedure. The mean particle size values $( \pm$ SD) for formulations number 1 to 15 , were $570.8 \pm(35.1), 549.9 \pm(41.5), 500.2 \pm(39.7)$, $490.2 \pm(39.8), 509.9 \pm(42.6), 599.8 \pm(32.9), 491.3 \pm$ (45.2), $466.8 \pm$ (47.9), $429.9 \pm$ (43.1), $470.1 \pm$ (39.2), 417.4 \pm (37.9),

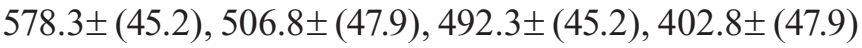
$\mu \mathrm{m}$ respectively So, the formulated TS microspheres were arranged according to the mean particle size, in descending order, as following: F6, F12, F1, F2, F5, F13, F3, F14, F7, F4, F10, F8, F9, F11 and F15. High stirring speed $(600 \mathrm{rpm})$ produced microspheres with small particle size while low stirring speed $(200 \mathrm{rpm})$ produced microspheres with large particle size. Similar results were obtained by chitosan coated soya oil containing lipophilic marker as well as plain Ch-Alg microspheres prepared by different crosslinking techniques (Ribeiro et al., 1999). Various manufacturing parameters (apparatus design, type of stirrer, stirring speed, the viscosity of emulsion phase, polymer concentration and emulsifier concentration) affect the particle size of the prepared microspheres (Xu et al., 2007).
$\mathrm{D}: \mathrm{P}$ ratio markedly affected the size of the microspheres at the three different Alg-Ch concentrations (Zhang et al., 2011). The mean particle size of the prepared microspheres increased with increasing the amount of the copolymers. No clear relationship was found between the particle size of the microspheres and the change in polymer concentrations ( $\mathrm{Xu}$ et al., 2007). Stirring speed is the most important parameter for controlling the drug/matrix dispersion's droplet size in the continuous phase. It was shown that increasing the stirring speed generally results in decreased microsphere size, as it produces smaller emulsion droplets through stronger shear forces and increased turbulence. The same results were obtained in the microencapsulation of ibuprofen with eudragit RS100 (Perumal, 2001).

\section{Microspheres production yield}

The percentage of production yields are listed in Table II. There was no obvious difference between the yield of different formulations on varying both the D:P ratio and the speed.

TABLE II - Production yield, actual drug content and \% EE of different TS Alg-Ch microspheres

\begin{tabular}{lcccc}
\hline $\begin{array}{l}\text { Formulation } \\
\text { number }\end{array}$ & $\begin{array}{c}\text { Yield } \\
\mathbf{( \% )}\end{array}$ & $\begin{array}{c}\text { Theoretical drug content } \\
(\%)\end{array}$ & $\begin{array}{c}\text { Actual drug content } \\
(\%) \text { Mean } \pm \text { SD }\end{array}$ & $\begin{array}{c}\text { Loading efficiency } \\
\text { (\%) }\end{array}$ \\
\hline 1 & $94.37 \pm 3.11$ & 50.00 & $37.93 \pm 1.51$ & 75.87 \\
2 & $87.62 \pm 4.23$ & 50.00 & $41.32 \pm 2.59$ & 82.64 \\
3 & $85.14 \pm 4.02$ & 50.00 & $45.15 \pm 1.08$ & 90.31 \\
4 & $88.06 \pm 5.08$ & 50.00 & $49.66 \pm 1.99$ & 99.32 \\
5 & $35.36 \pm 4.32$ & 33.33 & $31.74 \pm 1.85$ & 95.25 \\
6 & $92.80 \pm 3.98$ & 33.33 & $24.25 \pm 2.04$ & 72.76 \\
7 & $83.82 \pm 4.51$ & 33.33 & $26.37 \pm 0.94$ & 79.13 \\
8 & $78.40 \pm 4.11$ & 33.33 & $29.40 \pm 1.26$ & 88.23 \\
\hline 9 & $88.33 \pm 5.44$ & & $28.32 \pm 1.66$ & 84.99 \\
\hline
\end{tabular}


TABLE II - Production yield, actual drug content and \% EE of different TS Alg-Ch microspheres

\begin{tabular}{lcccc}
\hline $\begin{array}{l}\text { Formulation } \\
\text { number }\end{array}$ & $\begin{array}{c}\text { Yield } \\
\mathbf{( \% )}\end{array}$ & $\begin{array}{c}\text { Theoretical drug content } \\
\mathbf{( \% )}\end{array}$ & $\begin{array}{c}\text { Actual drug content } \\
\mathbf{( \% )} \text { Mean } \pm \text { SD }\end{array}$ & $\begin{array}{c}\text { Loading efficiency } \\
\mathbf{( \% )}\end{array}$ \\
\hline 10 & $86.82 \pm 4.51$ & 33.33 & $32.36 \pm 2.59$ & 97.11 \\
11 & $80.55 \pm 3.24$ & 33.33 & $28.96 \pm 2.59$ & 86.91 \\
12 & $89.07 \pm 4.43$ & 25.00 & $19.83 \pm 2.59$ & 79.33 \\
13 & $93.41 \pm 3.84$ & 25.00 & $17.72 \pm 2.59$ & 70.89 \\
14 & $86.29 \pm 5.84$ & 25.00 & $16.74 \pm 2.59$ & 66.98 \\
15 & $90.30 \pm 4.44$ & 25.00 & $23.13 \pm 2.59$ & 92.54 \\
\hline
\end{tabular}

\section{Differential scanning calorimetry (DSC)}

The drug may have been dispersed in crystalline or amorphous form or dissolved in the polymeric matrix during the formation of microspheres. Any abrupt or drastic change in the thermal behavior of either the drug or polymer may indicate possible drug-polymer interaction. The endothermic peak of the pure drug was observed at about $159.31^{\circ} \mathrm{C}$ (Figure 2). However, in the thermogram of the microspheres, (containing Alg and $\mathrm{Ch}$ ) there was an endothermic peak of the drug melting with a lower intensity than the pure drug peak, suggesting the crystalline state of the drug in the microspheres. The DSC showed the stable character of TS in the drug-loaded microspheres and revealed the crystallinity form. Similar results were observed with Nimodipine microspheres prepared by ionic gelation technique (Rajendran, Basu, 2009).

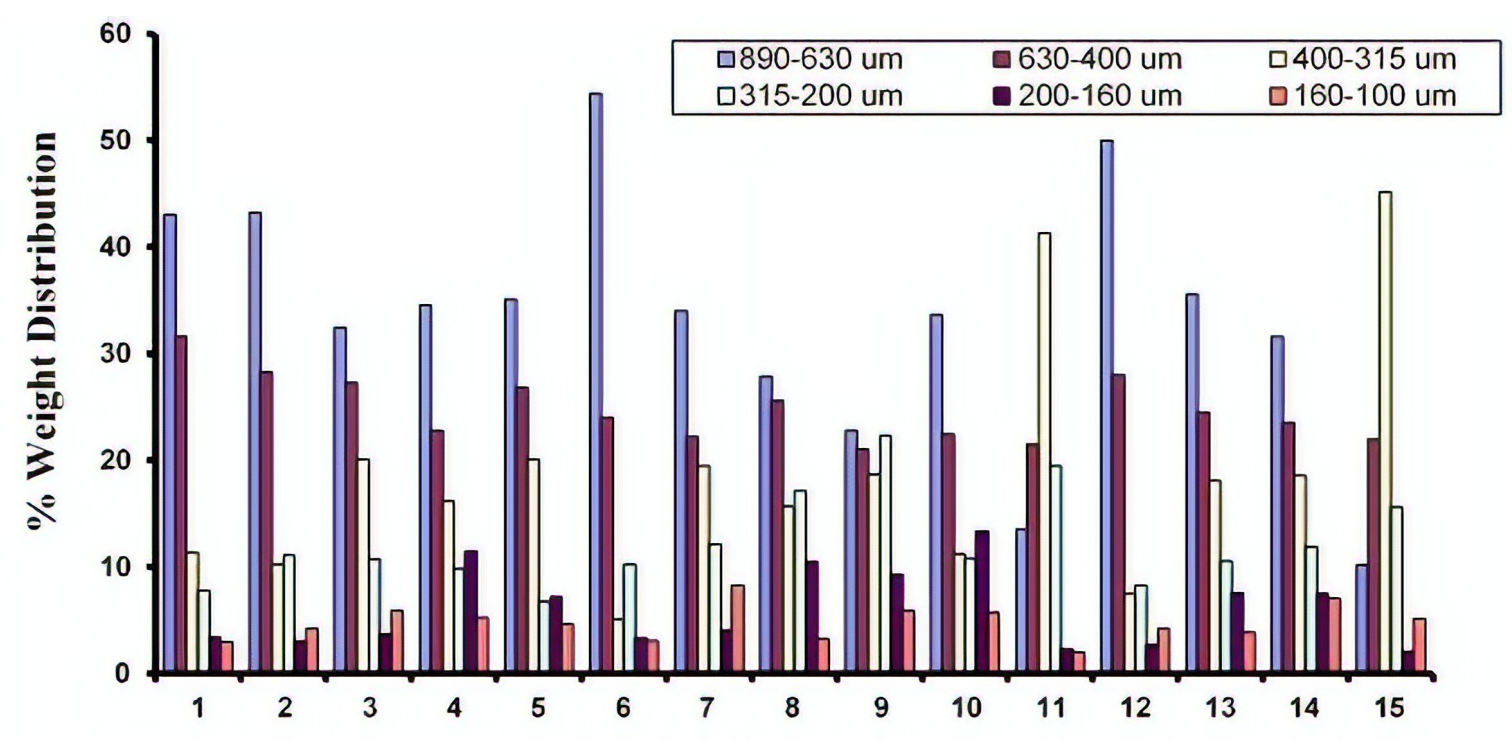

Formula number

FIGURE 2 - Histogram representing the fraction percent of \% weight distribution of different formulae of TS coated Alg-Ch microspheres. 


\section{Encapsulation Efficiency Percent (\% EE)}

The data obtained in the case of TS Ch-Alg microspheres are listed in Table II. According to D:P ratio, the calculated theoretical drug content value for formulations, number 2, 4 and 6 was $33.33 \%$, while for formulations, number 1,5 and 9 was $25 \%$ and for formulations number 3,7 and 8 was $20 \%$. Thus, the loading efficiency values $( \pm$ SD) for the nine formulations were computed as $88.4 \pm$ (4.56), 78.7 \pm (5.19), 75.6 \pm

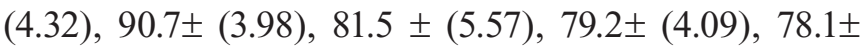
(3.79), 92.3 \pm (5.04), and $74.8 \pm(4.99) \%$. The effect of changing the D:P ratio on the drug loading efficiency was investigated, at each chitosan concentration, using the ANOVA test. TS \% EE values depended on the speed of rotation and were found to range from $74.8 \pm 3.67$ to $92.3 \pm 1.88$. The output shows the results of fitting a multiple linear regression model to describe the relationship between D: P ratio and $\% \mathrm{EE}$. The equation of the fitted model is:

$\% \mathrm{EE}=84.12+6.58 \mathrm{X}_{1}-4.80 \mathrm{X}_{2}-3.62 \mathrm{X}_{3}+6.48 \mathrm{X}_{1}^{2}$ - $3.83 \mathrm{X}_{2}^{2}-2.58 \% \mathrm{X}_{3}^{2}-2.56 \mathrm{X}_{1} \mathrm{X}_{2}+3.07 \mathrm{X}_{1} \mathrm{X}_{3}-2.89 \mathrm{X}_{1} \mathrm{X}_{3}$

TABLE III - Factors combinations and response parameters of TS Alg-Ch microspheres prepared with Box-Behnken design

\begin{tabular}{|c|c|c|c|c|c|c|}
\hline \multirow{2}{*}{$\begin{array}{l}\text { Formula } \\
\text { No. }\end{array}$} & \multicolumn{3}{|c|}{ Variable level in coded form } & \multicolumn{3}{|c|}{ Cumulative percent release } \\
\hline & $\mathbf{X} 1$ & $\mathbf{X} 2$ & $\mathbf{X} 3$ & $\% \operatorname{LE}(\% w / w)^{a}$ & $\operatorname{Rel}_{2}{ }^{a}$ & $\operatorname{Rel}_{8}{ }^{a}$ \\
\hline F1 & -1 & -1 & 0 & 75.87 & 16.46 & 76.56 \\
\hline $\mathrm{F} 2$ & 0 & -1 & -1 & 82.64 & 23.43 & 97.54 \\
\hline F3 & 0 & -1 & +1 & 90.31 & 20.34 & 94.70 \\
\hline $\mathrm{F} 4$ & +1 & -1 & 0 & 99.32 & 22.56 & 90.65 \\
\hline F5 & -1 & 0 & -1 & 95.25 & 18.77 & 70.65 \\
\hline F6 & -1 & 0 & +1 & 72.76 & 16.40 & 62.76 \\
\hline F7 & 0 & 0 & 0 & 79.13 & 22.99 & 81.76 \\
\hline F8 & 0 & 0 & 0 & 88.23 & 19.50 & 68.41 \\
\hline F9 & 0 & 0 & 0 & 84.99 & 20.22 & 78.21 \\
\hline F10 & +1 & 0 & -1 & 97.11 & 23.87 & 82.76 \\
\hline F11 & +1 & 0 & +1 & 86.91 & 22.88 & 85.34 \\
\hline F12 & -1 & +1 & 0 & 79.33 & 14.54 & 62.76 \\
\hline F13 & 0 & +1 & -1 & 70.89 & 21.57 & 73.54 \\
\hline F14 & 0 & +1 & +1 & 66.98 & 23.32 & 48.26 \\
\hline F15 & +1 & +1 & 0 & 92.54 & 20.76 & 66.34 \\
\hline
\end{tabular}

The parentheses in the data represent the decoded factor levels. $X_{1}$ represents drug to polymer ratio; $X_{2}$ represents speed, $X_{3}$

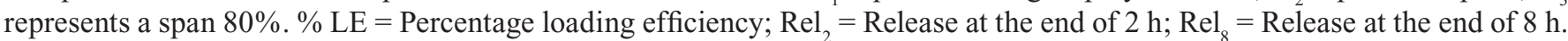
${ }^{a}$ The values represent the average of three determinations $(n=3)$ 
Since the P-value in the ANOVA table is greater or equal to 0.10 , there is not a statistically significant relationship between the variables at the $90 \%$ or higher confidence level. The R-Squared statistic indicates that the model as fitted explains $0.188324 \%$ of the variability in $\mathrm{D}: \mathrm{P}$ ratio. On the other hand, the output shows the results of fitting a multiple linear regression model to describe the relationship between speed and $\%$ EE. Since the P-value in the ANOVA table is less than 0.01 , there is a statistically significant relationship between the variables at the $99 \%$ confidence level. The R-Squared statistic indicates that the model as fitted explains $87.0527 \%$ of the variability in speed. The model indicated that the speed emerged as the lone factor, which exerted a significant influence on $\% \mathrm{EE}$.

The 3-D plot, Figure (3) showed that \%EE increased from $75.87 \pm 1.12$ to $99.32 \pm 0.62$ and from $79.33 \pm 1.61$ to $92.54 \pm 1.15$ at lower and higher levels of speed with a constant $\mathrm{D}: \mathrm{P}$ ratio. The improvement in $\% \mathrm{EE}$ with increased speed levels was due to the fact that more drug gets dissolved and incorporated in the polymer matrix with a high speed of rotation. A linear relationship between the two variables investigated on the percent drug incorporation was clearly seen from the corresponding contour plots which suggested that $\%$ EE can be enhanced using a high speed of rotation (Figure 4). Microencapsulation by the emulsification/ internal gelation method involves two major steps, the formation of stable droplets of the polymer solution with drug incorporated in as an emulsified system and the subsequent solidification of the droplets. These two steps have a significant effect on the size and encapsulation efficiency of microspheres. Similar results were obtained in the preparation of biodegradable paclitaxel loaded alginate microspheres for pulmonary delivery (Alipour, Montaseri, Tafaghodi, 2010).

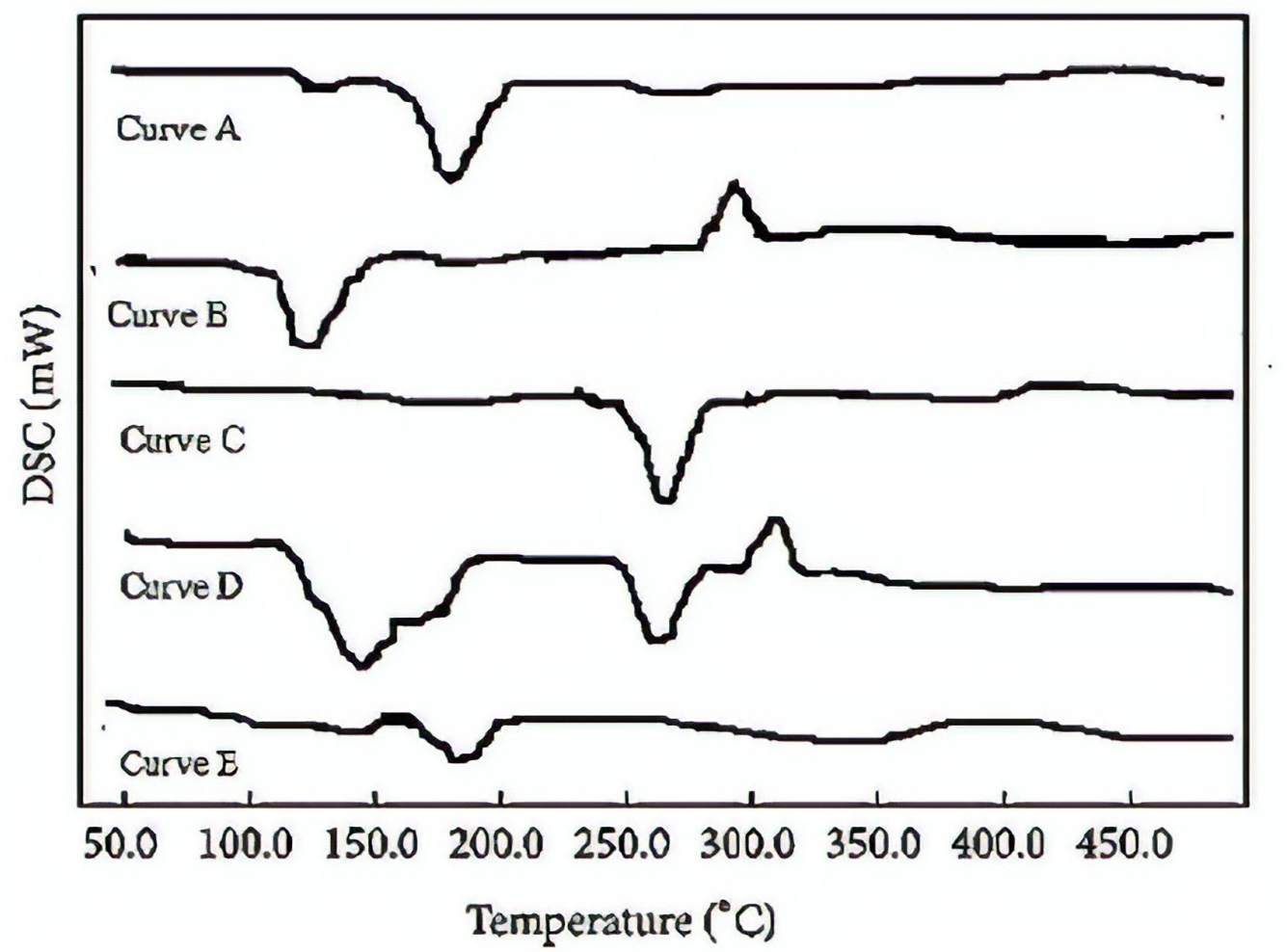

FIGURE 3 - Differential Scanning Calorimetry of TS (curve A), chitosn (curve B), sodium alginate (curve C), physical mixture (Curve D) and the prepared microspheres (curve E). 

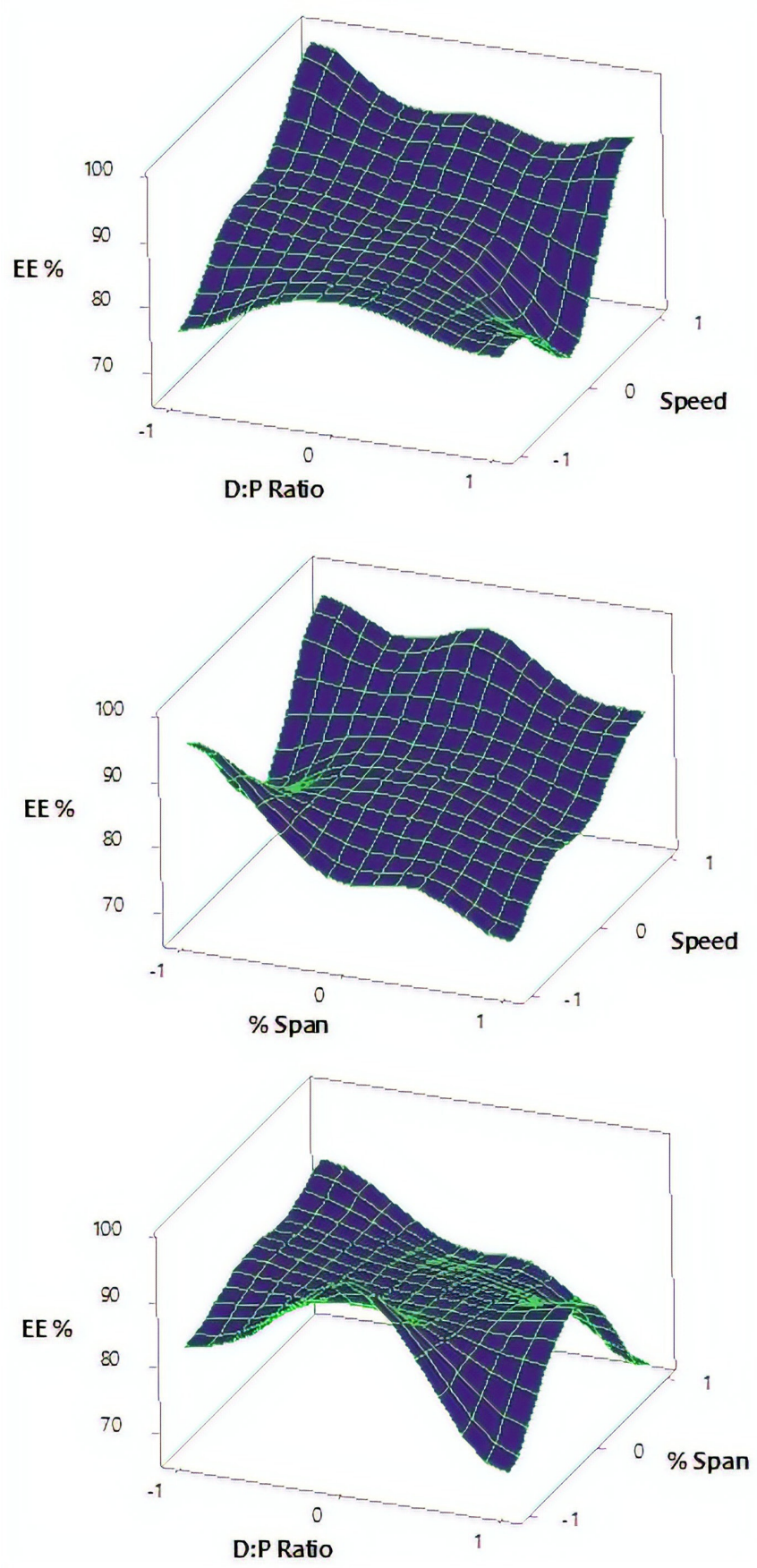

FIGURE 4 - Three-dimensional surface response plot for the effect of speed $\left(\mathrm{X}_{1}\right)$, D: $\mathrm{P}$ ratio $\left(\mathrm{X}_{2}\right)$ and span $80 \%\left(\mathrm{X}_{3}\right)$ on the drug loading efficiency $\left(\mathrm{Y}_{1}\right)$.

\section{In-vitro release of TS microspheres}

Figure 5 shows the in-vitro release of TS from its capsules containing formulae ( F1, F2, F3, and F4) using constant drug: polymer ratio 1:1 $\left(\mathrm{X}_{1}\right)$ with variable speed of rotations, $200 \mathrm{rpm}$ for F1; 400 for F2,3 and $600 \mathrm{rpm}$ for F4; $\left(\mathrm{X}_{2}\right)$. The maximum and minimum percent released was observed to be $23.43 \%$ and $16.46 \%$ at the end of two hours $\left(\mathrm{Y}_{2}\right)$. The maximum and the minimum in-vitro release after eight hours $\left(\mathrm{Y}_{3}\right)$ of dissolution were found to be equal to $97.54 \pm 3.32 \%$ and $76.56 \pm 1.76 \%$, respectively. These investigated formulae can be arranged, in descending order, concerning the in- vitro release within eight hours as follows: F2 $>$ F3 $>$ F4 $>$ F1 respectively.

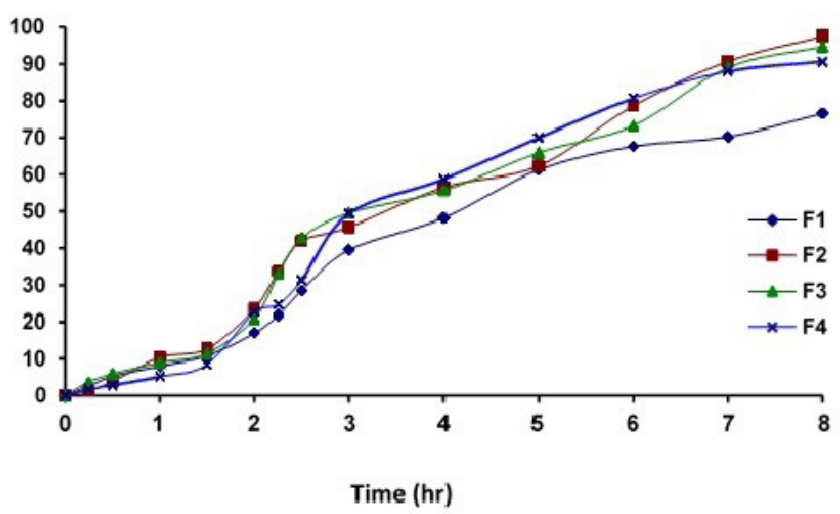

FIGURE 5 - In-vitro release of chitosan-coated TS Alg-Ch capsules containing drug: polymer ratio 1:1.

Figure 6 show the in-vitro release of TS from its capsules containing formulae F5, F6 F7, F8 F9, F10 and F11 using D:P ratiol:2 $\left(\mathrm{X}_{1}\right)$ with variable speeds, $200 \mathrm{rpm}$ for F5, F6; $400 \mathrm{rpm}$ for F7, F8, F9 and $600 \mathrm{rpm}$ for F10, F11 $\left(\mathrm{X}_{2}\right)$. The maximum and minimum percent released was observed to be $23.87 \pm 1.09 \%$ and $16.40 \pm 0.98 \%$ at the end of two hours $\left(\mathrm{Y}_{2}\right)$. The maximum and minimum in-vitro release after eight hours of dissolution $\left(\mathrm{Y}_{3}\right)$ was found to be $85.34 \pm 2.21 \%$ and $62.76 \pm 2.02 \%$. According to these results, these formulae can be arranged, in descending order, concerning the in-vitro release within 8 hours dissolution as follows: F11 $>$ F10 $>$ F7 $>$ F9 $>$ F5 $>\mathrm{F} 8>\mathrm{F} 6$ respectively.

The in-vitro release of TS from its capsules containing formulae F12, F13, F14, and F15 using constant drug-polymer ratio 1:4 $\left(\mathrm{X}_{1}\right)$ with variable speeds, $200 \mathrm{rpm}$ for F12; $400 \mathrm{rpm}$ for F13, F14 and $600 \mathrm{rpm}$ for F15 $\left(\mathrm{X}_{1}\right)$ Figure (7). The maximum and minimum percent released was observed to be $23.32 \pm 1.12$ and $14.54 \pm 1.14$ after the end of two hours $\left(\mathrm{Y}_{2}\right)$. The maximum and minimum in-vitro releases after eight hours $\left(\mathrm{Y}_{3}\right)$ of dissolution were found to be $73.54 \pm 2.67$ and $48.26 \pm 2.03 \%$. According to these results, these formulae can be arranged, in descending order, concerning the in-vitro release within 8 
hours dissolution as follows: F13 > F15> F12> F14 respectively.

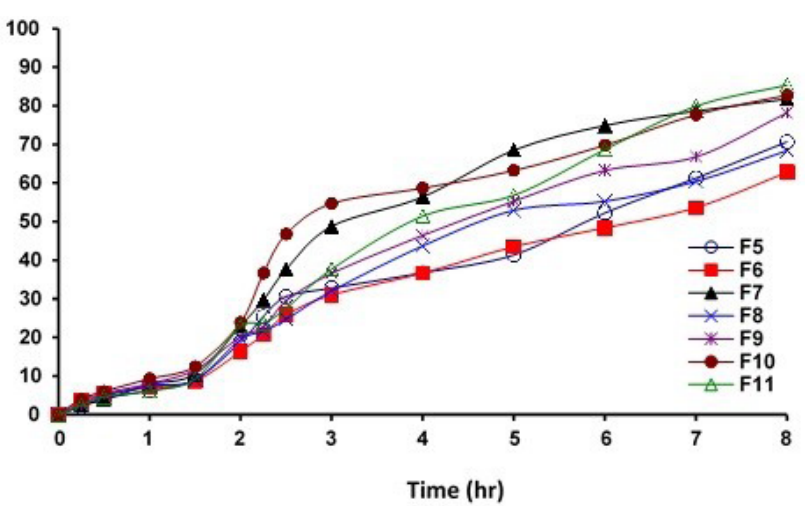

FIGURE 6 - In-vitro release of chitosan-coated TS Alg-Ch capsules containing drug: polymer ratio 1:2.

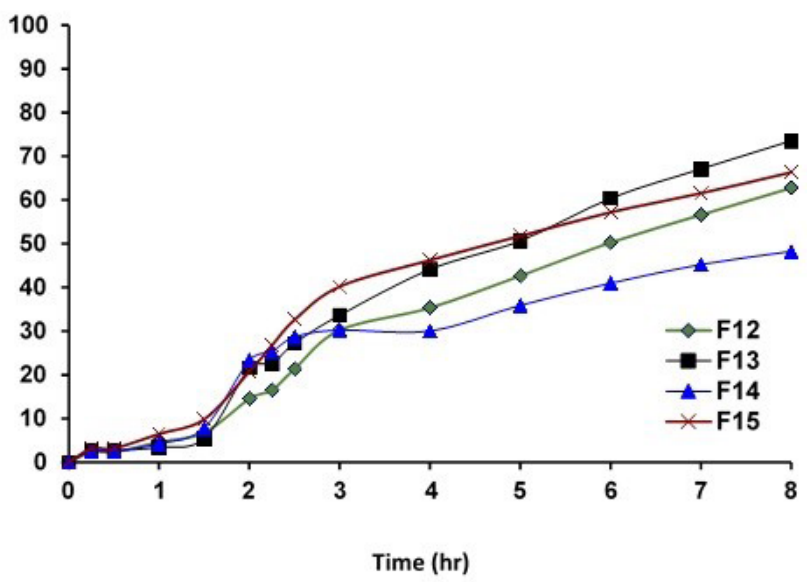

FIGURE 7 - In-vitro release of chitosan-coated TS Alg-Ch capsules containing drug: polymer ratio 1:3.

The best formulae for the in-vitro release after the whole dissolution period ( 8 hours) were observed to be F14, F12, and F6. The equation of the fitted model which study the effect of D:P Ratio and speed on drug release after 2 hours is

$\mathrm{Y}(2 \mathrm{hrs})=20.903+2.988 \mathrm{X}_{1}-0.325 \mathrm{X}_{2}-0.588 \mathrm{X}_{3}-2.004 \mathrm{X}_{1}^{2}-$ $0.319 \mathrm{X}_{2}^{2}+1.581 \mathrm{X}_{3}^{2}+0.030 \mathrm{X}_{1} \mathrm{X}_{2}+0.345 \mathrm{X}_{1} \mathrm{X}_{3}+$ $.210 \mathrm{X}_{2} \mathrm{X}_{3}$

Since the P-value in the ANOVA table is less than 0.01 , there is a statistically significant relationship between the variables at the $99 \%$ confidence level. The R-Squared statistic indicates that the model as fitted explains $98.5588 \%$ of the variability in release 2 hours. The drug-polymer ratios were found to have a negative influence on the drug release whereas the speed had a positive influence on the drug release.

The response surface plots (Figure 8) illustrate that the drug release at the end of two hours decreased from $16.46 \pm 1.54 \%$ to $14.54 \pm 1.23 \%$ and from $22.56 \pm 1.89$ to $20.76 \pm 1.42 \%$ at low and high levels of the drug to polymer ratio, respectively as the polymer content increased. This can be due to better incorporation of the drug in the polymeric matrices, which left behind fewer drug crystals on the surface with the increase in the polymer content.

The levels of speed were found to have a positive influence on the drug release after two hours. It was evident from the 3-D plots (Figure 7) that the drug release at the end of two hours increased from $16.46 \pm 1.21 \%$ to $22.56 \pm 1.32 \%$ and from $14.54 \pm 1.14 \%$ to $20.76 \pm 1.12 \%$ at low and high speed levels respectively. This increase in drug release was due to the decrease in particle size of prepared microspheres which increased the surface area available for drug diffusion and consequently increased the permeability of Alg-Ch copolymers. These results indicated that drug release could be minimized using low levels of speed at high polymer levels.

The equation of the fitted model which study the effect of drug-polymer ratio and speed on drug release after 8 hours is:

$\mathrm{Y} 8 \mathrm{hrs}=76.13+6.55 \mathrm{X}_{1}-13.57 \mathrm{X}_{2}-4.18 \mathrm{X}_{3}-2.59 \mathrm{X}_{3}^{2}$ $+0.54 \mathrm{X}_{2}^{2}+1.84 \mathrm{X}_{3}^{2}-2.63 \mathrm{X}_{3} \mathrm{X}_{2}+2.62 \mathrm{X}_{3} \mathrm{X}_{1}-5.61 \mathrm{X}_{2} \mathrm{X}_{3}$

Drug-polymer ratio and speed had a significant effect on drug release at the end of 8 hours with an $\mathrm{F}$ value of $165.35(p<0.0001)$. The R-Squared statistic indicates that the model as fitted explains $98.218 \%$ of the variability in 8 hours release. The drug-polymer ratios were found to have a negative influence on the drug release whereas the speed had a positive influence on the drug release.

The response surface plots (Figure 9) illustrate that the drug release at the end of eight hours decreased from $76.56 \pm 1.76 \%$ to $62.76 \pm 2.03 \%$ and from $90.65 \pm 3.32$ to $66.34 \pm 2.67 \%$ at low and high levels of D:P ratio, respectively as the polymer content increased. This can be due to better incorporation of the drug in the polymeric matrices, which left behind fewer drug crystals on the surface with an increase in the polymer content. 


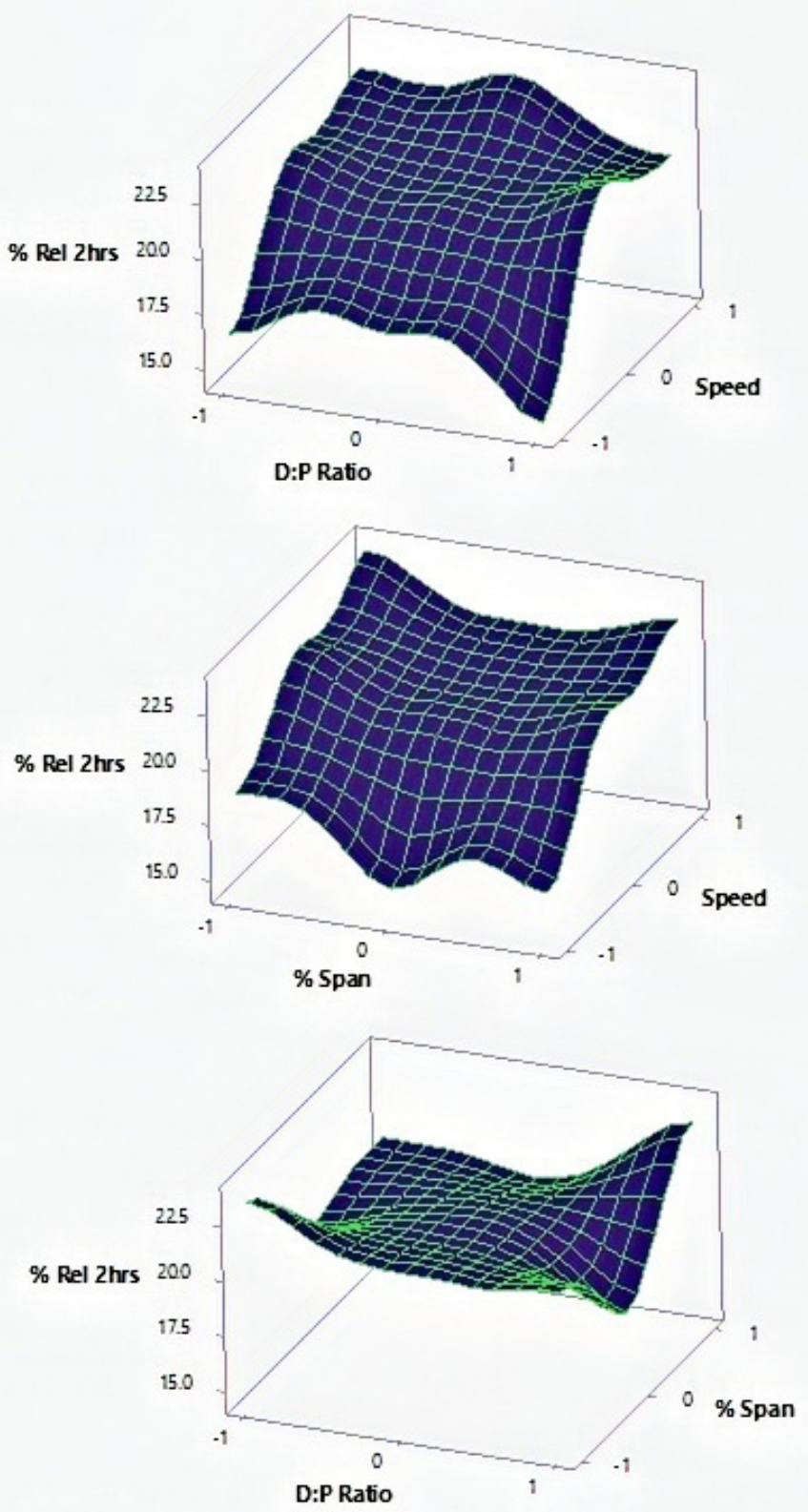

FIGURE 8 - Three-dimensional surface response plot for the effect of D: P ratio $\left(\mathrm{X}_{1}\right)$ and speed $\left(\mathrm{X}_{2}\right)$ on drug release after two hours $\left(\mathrm{Y}_{2}\right)$.

The release data of TS from Alg-Ch microspheres prepared with different process variables were analyzed according to zero and first-order kinetics as well as, Higushi diffusion-controlled mechanism Table 4. The release order of the drug was determined. It was found that the drug was released from the microspheres according to the zero-order pattern, at different drugs to polymer ratios. The release medium dissolves the drug after penetrating the microspheres wall by allowing the dissolved drug to diffuse out due to concentration gradient established between the interior of the microspheres and the release medium.
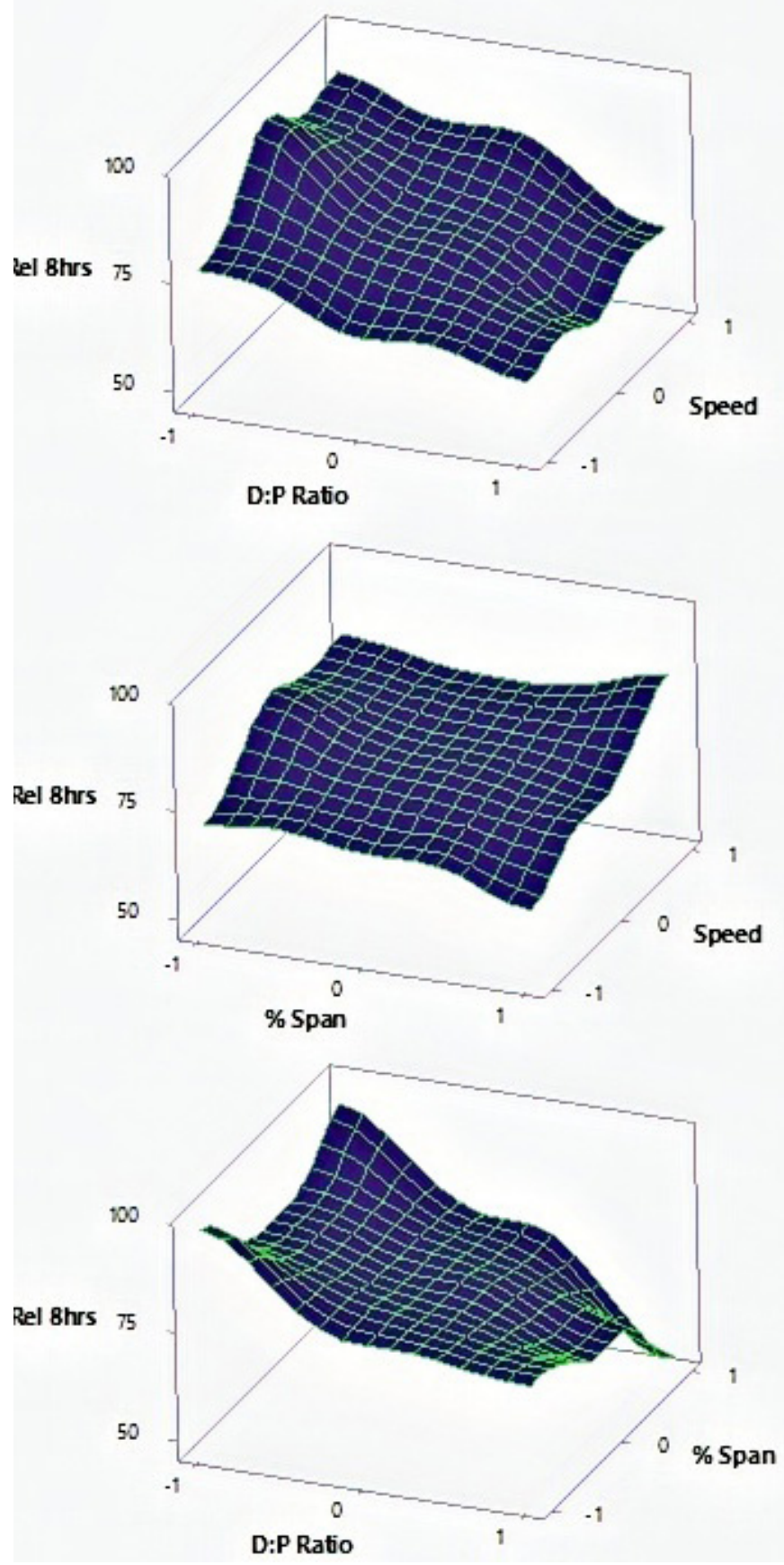

FIGURE 9 - Three-dimensional surface response plot for the effect of $\mathrm{D}$ : $\mathrm{P}$ ratio $\left(\mathrm{X}_{1}\right)$ and speed $\left(\mathrm{X}_{2}\right)$ on drug release after eight hours $\left(\mathrm{Y}_{3}\right)$. 
Controlled Release Alginate- Chitosan Microspheres of Tolmetin Sodium Prepared by Internal Gelation Technique and Characterized by Response Surface Modeling

TABLE IV - Analysis of the release data for TS microspheres prepared at a different drug: polymer ratios of sodium Alg-Ch mixture

\begin{tabular}{|c|c|c|c|c|c|c|c|c|c|c|c|c|c|c|c|c|}
\hline $\begin{array}{l}\text { Formula } \\
\text { number }\end{array}$ & & F1 & F2 & F3 & F4 & F5 & F6 & F7 & F8 & F9 & F10 & F11 & F12 & F13 & F14 & F15 \\
\hline \multirow{2}{*}{$\begin{array}{l}\text { Zero- } \\
\text { order }\end{array}$} & $\mathrm{K}_{\mathrm{z}}$ & 8.148 & 10.50 & 7.108 & 8.837 & 8.781 & 9.482 & 6.44 & 9.323 & 9.323 & 8.735 & 6.44 & 10.50 & 9.323 & 9.323 & 9.323 \\
\hline & $\mathrm{R}_{\mathrm{z}}$ & 0.984 & 0.991 & 0.968 & 0.981 & 0.984 & 0.989 & 0.961 & 0.986 & 0.986 & 0.982 & 0.961 & 0.991 & 0.986 & 0.986 & 0.986 \\
\hline \multirow{2}{*}{$\begin{array}{l}\text { First- } \\
\text { order }\end{array}$} & $\mathrm{K}_{\mathrm{f}}$ & 0.139 & 0.291 & 0.127 & 0.171 & 0.167 & 0.217 & 0.104 & 0.203 & 0.203 & 0.271 & 0.104 & 0.291 & 0.203 & 0.203 & 0.203 \\
\hline & $\mathrm{R}_{\mathrm{f}}$ & 0.962 & 0.942 & 0.952 & 0.960 & 0.958 & 0.966 & 0.948 & 0.963 & 0.963 & 0.930 & 0.948 & 0.942 & 0.963 & 0.963 & 0.963 \\
\hline \multirow{2}{*}{$\begin{array}{l}\text { Higuchi } \\
\text { equation }\end{array}$} & $\mathrm{K}_{\mathrm{h}}$ & 21.26 & 18.70 & 33.09 & 29.24 & 19.98 & 23.75 & 22.16 & 31.69 & 31.69 & 28.24 & 22.16 & 18.70 & 31.69 & 31.69 & 31.69 \\
\hline & $\mathrm{R}_{\mathrm{h}}$ & 0.924 & 0.990 & 0.967 & 0.976 & 0.971 & 0.985 & 0.960 & 0.976 & 0.976 & 0.936 & 0.960 & 0.990 & 0.976 & 0.976 & 0.976 \\
\hline
\end{tabular}

$\mathrm{K}_{\mathrm{z}}\left(\mathrm{mg} \cdot \mathrm{hr}^{-1}\right), \mathrm{K}_{\mathrm{f}}\left(\mathrm{hr}^{-1}\right)$ and $\mathrm{K}_{\mathrm{h}}\left(\mathrm{mg} / \mathrm{cm}^{2} . \mathrm{hr}^{1 / 2}\right)$ are the release rate constants of zero-order, first order and, Higuchi model kinetics, respectively, as well as $R_{z}, R_{f}$ and $R_{h}$ are their corresponding correlation coefficients.

\section{In-vivo studies}

The anti-inflammatory effect of TS microspheres and the commercial tablet on the size of edema induced in the right hind paw of rats induced by carrageenan (Onishi et al., 2010). Treatment of the rats with TS microspheres and tablet significantly inhibit the edema size induced by carrageenan injection in the intraplantar area of the right hind paw at the therapeutic dose level for the rats $2 \mathrm{mg} / \mathrm{kg}$ ) (Solanki et al., 2015). It was observed that group two (treated with commercial tablet) produced the maximum percent edema inhibition at 8 hours and the effect decreased gradually with time up to 10 hours. Regarding the anti-inflammatory activity of TS microspheres, F12 and F6 of TS-Alg-Ch showed the highest inhibitory effect at 8 hours after the injection of carrageenan (percentage of edema inhibition was 62.71 and $58.76 \%$, respectively).

These results are illustrated in Figure 10. The maximum anti-inflammatory activity of the selected formulation higher than that of TS commercial tablet. After ten hours both groups still showing the antiinflammatory activity. The ANOVA of the results of the anti-inflammatory activity of TS formulation on edema size. From this table, we noted that as a whole set of experiment, all the investigated formulae were significantly inhibiting edema size and the p-value less than 0.05 were considered as significant.

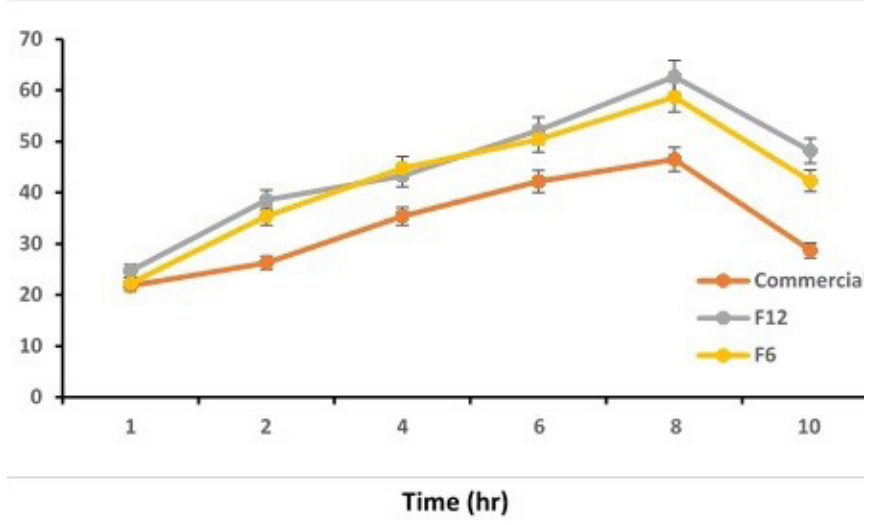

FIGURE 10 - Effect of TS formulations on the inhibition of rat hind paw edema induced by carrageenan.

\section{CONCLUSION}

Coating the alginate microspheres with chitosan delayed the drug release by forming Alg-Ch complex. The microspheres were spherical in shape with large pores at D: $\mathrm{P}$ ratiol:1 while at 1:3 D:P ratio formed microspheres 
having a smooth surface and small pores. The change in chitosan concentration had a non-significant effect on drug $\mathrm{EE} \%$. Increasing $\mathrm{Ch}$ concentration decreased the drug release significantly. The increase in the speed of rotation had significantly decreased drug loading efficiency, while it is significantly increased the drug release. TS Alg-Ch microspheres followed zero-order release kinetics. The selected formulae TS microspheres give a significant inhibition of rat paw edema. The behavior of the TS Alg-Ch microspheres is of great interest for the delivery of the non-steroidal antiinflammatory drug into the small intestine.

\section{REFERENCES}

Ahmed MM, El-Rasoul SA, Auda SH and Ibrahim MA. Emulsification/internal gelation as a method for preparation of diclofenac sodium-sodium alginate microparticles. Saudi Pharm J. 2013; 21(1): 61-69.

Alipour S, Montaseri H and Tafaghodi M. Preparation and characterization of biodegradable paclitaxel loaded alginate microparticles for pulmonary delivery. Coll Surf B Bioint. 2010; 81(2): 521-529.

Chan L, Lee $\mathrm{H}$ and Heng P. Production of alginate microspheres by internal gelation using an emulsification method. Int $J$ of Pharm. 2002; 242(1-2): 259-262.

Chen L and Subirade M. Effect of preparation conditions on the nutrient release properties of alginate-whey protein granular microspheres. Europ J of Pharm and Bioph. 2007; 65(3): 354-362.

Dean A, Voss D and Draguljić D (2017). Response surface methodology. Des and analy of exp, Springer: 565-614.

El-Shenawy AA, Ahmed MM, Mansour HF and El Rasoul SA. Torsemide Fast Dissolving Tablets: Development, Optimization Using Box-Bhenken Design and Response Surface Methodology, In Vitro Characterization, and Pharmacokinetic Assessment. AAPS PharmSciTech. 2017; 18(6): 2168-2179.

Higuchi T. Mechanism of sustained-action medication. Theoretical analysis of rate of release of solid drugs dispersed in solid matrices. J Pharm Sci. 1963; 52(12): 1145-1149.

Jelvehgari M, Nokhodchi A, Rezapour M and Valizadeh $\mathrm{H}$. Effect of formulation and processing variables on the characteristics of tolmetin microspheres prepared by double emulsion solvent diffusion method. Ind J Pharm Sci. 2010; 72(1): 72-78.
Motwani SK, Chopra S, Talegaonkar S, Kohli K, Ahmad FJ and Khar RK. Chitosan-sodium alginate nanoparticles as submicroscopic reservoirs for ocular delivery: formulation, optimisation and in vitro characterisation. Europ $J$ of Pharm and Biopharm. 2008; 68(3): 513-525.

Nath B, Nath LK, Mazumder B, Kumar P, Sharma N and Sahu BP. Preparation and characterization of salbutamol sulphate loaded ethyl cellulose microspheres using water-in-oil-oil emulsion technique. Iran J of Pharm Res. 2010; 9(2): 97.

Onishi H, Koyama K, Sakata O and Machida Y. Preparation of chitosan/alginate/calcium complex microparticles loaded with lactoferrin and their efficacy on carrageenan-induced edema in rats. Drug dev and ind pharm. 2010; 36(8): 879-884.

Palmieri GF, Bonacucina G, Di Martino P and Martelli S. Microencapsulation of semisolid ketoprofen/polymer microspheres. Int $J$ of Pharm. 2002; 242(1-2): 175-178.

Pandey R and Khuller G. Chemotherapeutic potential of alginate-chitosan microspheres as anti-tubercular drug carriers. J of Antimic Chem. 2004; 53(4): 635-640.

Paredes Juárez GA, Spasojevic M, Faas MM and de Vos P. Immunological and technical considerations in application of alginate-based microencapsulation systems. Fron in Bioeng and Biotech. 2014; 2: 26.

Pasparakis G and Bouropoulos N. Swelling studies and in vitro release of verapamil from calcium alginate and calcium alginate-chitosan beads. Int $J$ of Pharm. 2006; 323(1-2): $34-42$.

Perumal D. Microencapsulation of ibuprofen and Eudragit RS 100 by the emulsion solvent diffusion technique. Int $J$ of Pharm. 2001; 218(1-2): 1-11.

Rajendran A and Basu SK. Alginate-chitosan particulate system for sustained release of nimodipine. Trop J Pharm Res. 2009; 8(5).

Rajinikanth P, Sankar C and Mishra B. Sodium alginate microspheres of metoprolol tartrate for intranasal systemic delivery: development and evaluation. Drug Deliv. 2003; 10(1): 21-28.

Ribeiro AJ, Neufeld RJ, Arnaud P and Chaumeil JC. Microencapsulation of lipophilic drugs in chitosan-coated alginate microspheres. Int J of Pharm. 1999; 187(1): 115-123.

Silva CM, Ribeiro AJ, Figueiredo IV, Gonçalves AR and Veiga F. Alginate microspheres prepared by internal gelation: Development and effect on insulin stability. Int $J$ of Pharm. 2006; 311(1-2): 1-10. 
Sipahigil O and Dortunc B. Preparation and in vitro evaluation of verapamil $\mathrm{HCl}$ and ibuprofen containing carrageenan beads. Int $J$ of Pharm. 2001; 228(1-2): 119-128.

Solanki HK, Shah DA, Maheriya PM and Patel CA. Evaluation of anti-inflammatory activity of probiotic on carrageenaninduced paw edema in Wistar rats. Int J of Biol Mac. 2015; 72: $1277-1282$.

Thaya R, Vaseeharan B, Sivakamavalli J, Iswarya A, Govindarajan M, Alharbi NS, et al. Synthesis of chitosanalginate microspheres with high antimicrobial and antibiofilm activity against multi-drug resistant microbial pathogens. Micro Path. 2018; 114: 17-24.

van Zwol P, Palasantzas G, Van De Schootbrugge M, De Hosson JTM and Craig V. Roughness of microspheres for force measurements. Langmuir. 2008; 24(14): 7528-7531.

Xu Y, Zhan C, Fan L, Wang L and Zheng H. Preparation of dual crosslinked alginate-chitosan blend gel beads and in vitro controlled release in oral site-specific drug delivery system. Int J of Pharm. 2007; 336(2): 329-337.

Yetilmezsoy K, Demirel S and Vanderbei RJ. Response surface modeling of $\mathrm{Pb}$ (II) removal from aqueous solution by Pistacia vera L.: Box-Behnken experimental design. $J$ of Haz Mat. 2009; 171(1-3): 551-562.

Zhang Y, Wei W, Lv P, Wang L and Ma G. Preparation and evaluation of alginate-chitosan microspheres for oral delivery of insulin. Europ J of Pharm and Biopharm. 2011; 77(1): 11-19.

Zou Q, Zhao J, Liu X, Tian F, Zhang Hp, Zhang H, et al. Microencapsulation of Bifidobacterium bifidum F-35 in reinforced alginate microspheres prepared by emulsification/internal gelation. Int $J$ of Food Sci \& Tech. 2011; 46(8): 1672-1678.

Received for publication on $07^{\text {th }}$ June 2018 Accepted for publication on $01^{\text {st }}$ February 2019 